\title{
Experience with sliding-clip splenorrhaphy for splenic injury during radical nephrectomy
}

\author{
Subhasis K. Giri, MD; Mamoun Abdelrahman, MD; Hugh D. Flood, MD
}

University Hospital Limerick, St. Nessan's Road, Limerick, Ireland

Cite as: Can Urol Assoc J 2015;9(7-8):E476-9. http://dx.doi.org/10.5489/cuaj.2732 Published online July 17, 2015.

\section{Abstract}

Introduction: We report our experience with sliding-clip splenorrhaphy (SCS), a novel splenic conservation technique, for iatrogenic splenic injury (ISI) during a left radical nephrectomy (RN). We also reviewed the literature on ISI.

Methods: We retrospectively reviewed data from patients who had RN between January 2005 and December 2013 at our institution. The technique used was similar to sliding-clip renorrhaphy. Our Medline literature identified articles containing "splenic injury during nephrectomy," "iatrogenic splenic injury." "iatrogenic splenectomy," and "splenorrhaphy." Our primary outcome measures included incidence of splenic injury and splenic conservation rate and splenectomy.

Results: Among the 370 RN, 140 were left sided. ISI injury occurred in 6 left RN (incidence 1.6\% for all nephrectomies, $4.2 \%$ for leftsided nephrectomies). All 6 cases had open procedure and for the left-sided procedure. Splenic conservation was attempted in 4 patients using SCS and 3 out of 4 were successfully repaired. Altogether 3 patients had splenectomy (incidence $0.8 \%$ for all nephrectomies, $2.1 \%$ for left-sided nephrectomies). Our literature review revealed that the incidence of iatrogenic splenectomy during left nephrectomy varies from $1.3 \%$ to $13.2 \%$.

Conclusions: SCS is an acceptable novel splenic conservation technique due to its ease of use and success in selected patients with ISI. There is little evidence on the true incidence of ISI especially on splenic conservation during nephrectomy. Every attempt at splenic conservation is likely to improve immediate- and long-term patient outcomes.

\section{Introduction}

Nephrectomy is a common urological operation for a variety of reasons, such as renal tumour, non-functioning kidney, and xantho-granulomatous pyelonephritis. Intra-operative complications of nephrectomy include varying degree of blood loss, pleural damage, and splenic injury. ${ }^{1}$ Splenic injury may also occur from external trauma or spontaneous rupture. Besides left nephrectomy, iatrogenic splenic injury (ISI) may happen during left hemi-colectomy, left adrenalectomy, and retroperitoneal lymph node dissection. ${ }^{2}$

latrogenic splenectomy may lead to the risk of subsequent overwhelming post-splenectomy infection (OPSI) and longterm risk of cardiovascular complications. ${ }^{3}$ Furthermore iatrogenic splenectomy during left radical nephrectomy (RN) is associated with adverse perioperative outcomes and possibly diminished survival. ${ }^{4}$ The true incidence of ISI during nephrectomy is unknown and there is no report in the literature on splenic salvage using sliding-clip splenorrhaphy (SCS).

We report our experience and outcomes with SCS, a novel splenic conservation technique, for ISI during RN. We also reviewed the literature on the incidence of splenic injury, iatrogenic splenectomy, and splenic salvage during left nephrectomy.

\section{Methods}

We retrospectively reviewed hospital data from patients who had RN between January 2005 and December 2013 at our institution. We included patients who had a left RN. We excluded patients who had simple nephrectomy and nephro-ureterectomy. Medical records were studied in detail to determine the histological diagnosis and stage. Attention was paid to any associated iatrogenic injury to spleen.

The author's (SG) technique of sliding clip splenorrhaphy was similar (with some modification) to the sliding-clip renorrhaphy now commonly used to close a renal defect after partial nephrectomy (Fig. 1). This was initially described by Sing and colleagues ${ }^{5}$ and then popularized by Bhayani and Figenshau. ${ }^{6}$ Using the sliding-clip technique, we inserted two or three sutures across the splenic tear with good con- 
trol of hemostasis. No. 0 polyglactin sutures on a computed tomography $(\mathrm{CT})$ needle was prepared by cutting to a length of $15 \mathrm{~cm}$, tying triple knot at the end, and placing a purple Hem-o-Lock clip proximal to the knot. These sutures were then placed through the capsule and omental fat about $1 \mathrm{~cm}$ away from the cut margin at intervals of $1 \mathrm{~cm}$. Another purple Hem-O-Lok clip was placed on the needle side of the suture in such a way that the suture passed through the centre of the Hem-o-Lock clip. This clip then slid towards the capsule over a strip of greater omentum to exert horizontal compression effect at the edge of the splenic tear. A second or third 0 polyglactin suture on the CT needle may be placed to complete the repair and hemostatic closure of the defect.

Our Medline literature identified articles containing "splenic injury during nephrectomy," "iatrogenic splenic injury," "iatrogenic splenectomy," and "splenorrhaphy." The relevant articles in English language were obtained as well as the relevant papers from their reference lists. We looked into different aspects of iatrogenic splenic injury in general and in relation to radical left nephrectomy.

Our primary outcome measures were splenic conservation rate, incidence of splenic injury, and splenectomy. Secondary outcome measures included incidence of ISI, splenectomy, and splenic conservation.

\section{Results}

Among the 370 left RNs, 140 were left sided. Of these, 130 were histologically renal cell carcinoma (RCC). Ten cases of oncocytoma were encountered.

ISI occurred in 6 left RNs (incidence 1.6\% for all nephrectomies, $4.2 \%$ for left-sided nephrectomies) in our series. All 6 cases had open procedure through subcostal incision. Splenic conservation was attempted in 4 patients using sliding-clip splenorrhaphy and 3 out of 4 were successfully repaired. In 1 patient, we attempted sliding clip renorrhaphy for deep hilar splenic tear, but it failed. Altogether 3 patients had splenectomy (incidence $0.8 \%$ for all nephrectomies and $2.1 \%$ for left sided nephrectomies).
Our literature review revealed that the incidence of iatrogenic splenectomy during left nephrectomy varies from $1.3 \%$ to $13.2 \% .^{7,8}$ In the largest series of 418 cases, the incidence was detected at $4.3 \% .^{9}$ There is little data on the true incidence of splenic injury, indications of splenectomy, and any attempt of splenic salvage during left nephrectomy (Table 1). There is no literature on splenic salvage using SCS; we report the details of our cases in which SCS was attempted.

\section{Case 1}

A 67-year-old man underwent open left RN (OLRN) for an incidental finding of $15-\mathrm{cm}$ upper pole renal mass. At the end of the procedure, continuing bleeding was observed from the surface of the spleen. A $2-\mathrm{cm}$ long and a $1-\mathrm{cm}$ deep splenic tear were identified at the colic surface near the inferior border of the spleen. Using sliding clip technique, we inserted 2 sutures across the splenic tear with good hemostasis control.

\section{Case 2}

A 58-year-old man presented with hematuria, flank pain, and anemia. A CT scan revealed a $17-\mathrm{cm}$ upper pole left renal complex cystic mass radiologically suspicious of RCC. OLRN was performed through a subcostal incision. The colic surface of the spleen (3-cm long and 1-cm deep) was inadvertently injured during mobilization of the splenic flexure and left colon and tail of the pancreas. SCS was applied successfully with preservation of the spleen.

\section{Case 3}

A 54-year-old man presented with left upper quadrant pain and imaging revealed a $19-\mathrm{cm}$ complex cystic radiologically suspicious mass in the region of the upper pole of left kidney. During OLRN, a $3 \times 1$-cm tear was noted near the hilum of the spleen. SCS was attempted but unsuccessful.

\begin{tabular}{|c|c|c|c|c|c|}
\hline Study & $\begin{array}{c}\text { Left } \\
\text { nephrectomies }\end{array}$ & $\begin{array}{l}\text { Splenic } \\
\text { injury }\end{array}$ & $\begin{array}{c}\text { latrogenic } \\
\text { splenectomy }\end{array}$ & $\begin{array}{c}\text { Splenic } \\
\text { conservation }\end{array}$ & Risk factor \\
\hline Mejean et al $2002^{7}$ & 233 & $1.7 \%$ & $1.3 \%$ & 1 & Colon mobilization \\
\hline $\begin{array}{l}\text { Carmignani G et al., } 2001^{8}- \\
\text { first group }\end{array}$ & 256 & $13.2 \%$ & $13.2 \%$ & Not reported & Anterolateral transabdomninal incision \\
\hline $\begin{array}{l}\text { Carmignani G et al } 2001^{8}- \\
\text { second group }\end{array}$ & 77 & $2.6 \%$ & $2.6 \%$ & Not reported & Cruciate Mercedes-Benz incision \\
\hline Cooper CS et al., $1996^{9}$ & 418 & $4.3 \%$ & $4.3 \%$ & Not reported & Advanced age and upper pole tumours \\
\hline Tan et al., $2011^{11}$ & 234 & $5.13 \%$ & $5.13 \%$ & Not reported & Colon mobilization \\
\hline Swanson et al., $1983^{12}$ & 193 & $12.4 \%$ & $12.4 \%$ & Not reported & Colon mobilization \\
\hline Current study & 140 & $4.2 \%$ & $1.2 \%$ & 3 & $\begin{array}{l}\text { Colon mobilization, Mobilisation of pancreas } \\
\text { and the mass in the upper pole of kidney }\end{array}$ \\
\hline
\end{tabular}


Giri et al.

Thus the patient had splenectomy for continuing bleeding from the splenic tear.

\section{Case 4}

A 64-year-old female underwent OLRN for a 14-cm radiologically suspicious mass in the left kidney through subcostal incision. Splenic tear $(2 \times 2 \mathrm{~cm})$ was noted on the inferior surface of the spleen $4 \mathrm{~cm}$ away from the hilum of the spleen. This was successfully repaired using SCS.

\section{Discussion}

The true incidence of iatrogenic splenectomy in general is difficult to assess and may be under reported. ${ }^{10}$ The incidence of iatrogenic splenectomy during a left nephrectomy is between $1.4 \%$ and $24 \% .{ }^{4}$ In a large series of 418 nephrectomies, $18(4.3 \%)$ resulted in splenectomy via a transperitoneal approach. Patients with a large or upper pole renal lesion, malignancy or advanced age were likely to undergo unanticipated splenectomy. ${ }^{9}$

Wang and colleagues ${ }^{4}$ recently evaluated risk factors associated with iatrogenic splenectomy during $\mathrm{RN}$ and outcomes among patients undergoing nephrectomy for renal tumours. There found a higher risk of iatrogenic splenectomy in patients with locally advanced tumours $(\geq \mathrm{pT} 3)$. latrogenic splenectomy was associated with adverse perioperative outcomes and diminished survival.

The true incidence of splenic injury during nephrectomy is poorly reported in most series. Mejean and colleagues reported 1 of 4 splenic injuries treated conservatively.

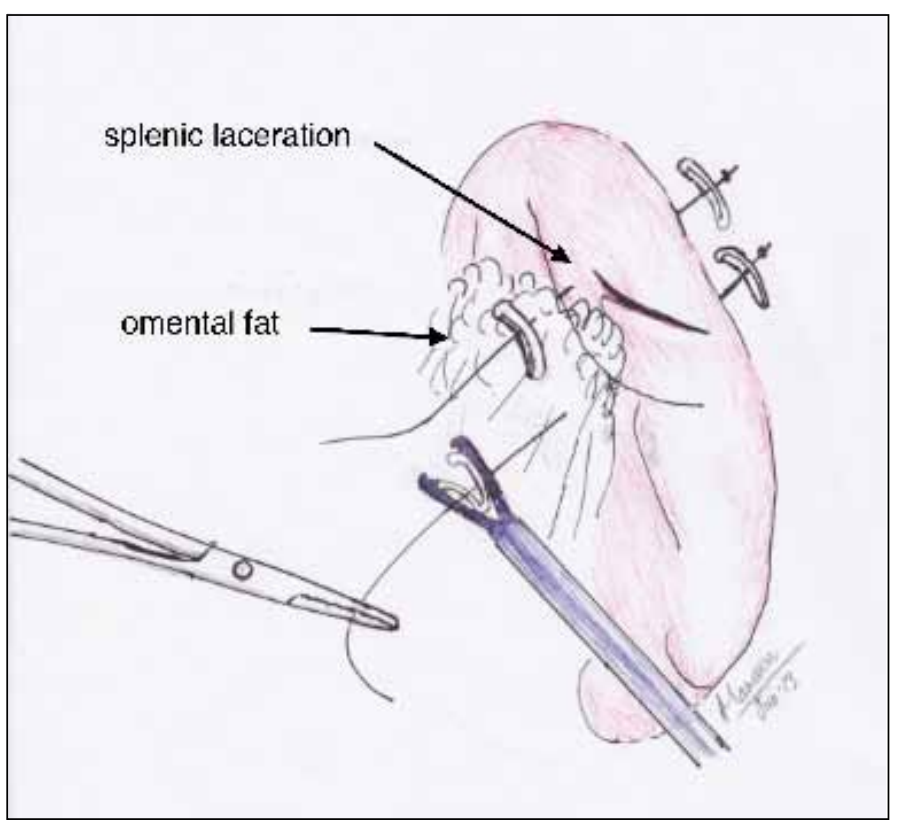

Fig. 1. Technique of Sliding-clip splenorrhaphy.
Carmignai and colleagues reported a reduction in iatrogenic splenectomy from $13.2 \%$ to $2.6 \%$ after they switched their skin incision from a subcostal anterolateral transabdominal one to a cruciate Mercedes-Benz incision. ${ }^{8}$

ISIs are caused by a variety of factors, such as mobilization of the colon, division of adhesion, mobilization of the pancreas, and inadvertent trauma from retractor. ${ }^{11,12}$ There has been an increased tendency in recent years towards splenic preservation to prevent not only the risk of subsequent overwhelming post-splenectomy infection (OPSI), but also the long-term risk of cardiovascular complications. ${ }^{3}$ Thus splenic conservation is desirable.

Repairing rather than removing the spleen is a surgical option that involves judgment, surgical skill, and experience. Splenectomy is the easiest and quickest technical procedure, and with experience, control of blood loss from the spleen and repair can be expeditiously achieved. Various techniques have been described for splenic preservation following splenic injury. Options include Dexon mesh splenorrhaphy, removing devitalized segments of the spleen with the use of the ultrasonic dissector, the suture ladder of Buntain, segmental and splenic arterial ligation with segmental resection, interlocking suture, long straight needles, hemostatic pledgets, and viable omentum as bolsters or packing. The use of stretchable mesh allows considerable liberty in the management of complex injuries of the spleen. ${ }^{13}$ Although there was initial concern about infection, the Dexon mesh splenorrhaphy has been effectively used to control splenic bleeding due to intraoperative injury. ${ }^{14,15}$

Topical application of hemostatic agents is one method of splenic preservation. ${ }^{16,17}$ Canby-Hagino and colleagues reported the use of fibrin sealant in 2 patients: the first one underwent open and the second was laparoscopic left nephrectomy and both were complicated by splenic laceration. ${ }^{16}$ However, this was likely due to a superficial tear of the splenic capsule. In deep splenic tear, we recommend a sliding clip splenorrhaphy.

Our series has its limitations. Sliding clip splenorrhaphy was applied to only 4 of our patients because the surgeon (SG) was involved in the procedure and the remaining 2 splenectomies were done by other surgeons. The author (SG) has already been using the sliding clip renorrhaphy technique in partial nephrectomy and applied the same principle in these cases. However not all patients may be suitable for this. Patients with a deep capsular tear near the hilum of the spleen are unlikely to benefit (as in our case 3), because of adjacent hilar vessels and little to support the parenchyma to compress the Hem-o-Lok clips.

\section{Conclusion}

This, to our knowledge, is the first report of splenic conservation using sliding-clip splenorrhaphy for ISI. Sliding-clip 
splenorrhaphy is an acceptable novel splenic conservation technique due to its ease of use and success in selected patients with ISI. There is little data on the true incidence of ISI, especially on splenic conservation during nephrectomy. Every attempt at splenic conservation is likely to improve immediate- and long-term patient outcomes.

Competing interests: The authors declare no competing financial or personal interests.

This paper has been peer-reviewed.

\section{References}

1. Van Poppel H, Da Pozzo L, Albrecht W, et al. A prospective randomized EORTC intergroup phase 3 study comparing the complications of elective nephron-sparing surgery and radical nephrectomy for low-stage renal cell carcinoma. Eur Urol 2007;51:1606-15. http://dx.doi.org/10.1016/i.eururo.2006.11.013

2. Coon WW. latrogenic splenic injury. Am J Surg 1990;159:585-8. http://dx.doi.org/10.1016/S00029610(06) 80072-3

3. Weledii EP. Benefits and risks of Splenectomy. Int I Surg 2013;S1743;1117-5.

4. Wang JK, Tollefson MK, Kim SP, et al. latrogenic splenectomy during nephrectomy for renal tumors. Int J Urol 2013;20:896-902. http://dx.doi.org/10.1111/iju.12065

5. Singh D, Rubenstein M, Gill IS. Laparoscopic partial nephrectomy. J Endourol 2005;19:451-5. http:// dx.doi.org/10.1089/end.2005.19.451

6. Benway BM, Cabello JM, Figenshau RS, et al. Sliding-clip renorrhaphy provides superior closing tension during robot-assisted partial nephrectomy. J Endourol 2010;24:605-8. http://dx.doi.org/10.1089/ end.2009.0244
7. Mejean $A$, Chretien $Y$, Vogt B, et.al. Coloepiploic mobilization during left radical nephrectomy for renal cell carcinoma is indicated to reduce the risk of iatrogenic splenectomy. Urology 2002;59:358-61. http:// dx.doi.org/10.1016/50090-4295(01)01549-7

8. Carmignani $G$, Traverso $P$, Corbu $C$. Incidental splenectomy during left radical nephrectomy: Reasons and ways to avoid it. Urol Int 2001;67:195-8. http://dx.doi.org/10.1159/000050986

9. Cooper CS, Cohen MB, Donovan JF Jr. Splenectomy complicating left nephrectomy. J Urol 1996;155:30-6. http://dx.doi.org/10.1016/S0022-5347(01)66530-3

10. Cassar K, Munro A. latrogenic splenic injury. J R Coll Surg Edinb 2002;47:731-41.

11. Tan K, Lewis $G R$, Chahal $R$, et al. Iatrogenic splenectomy during left nephrectomy: A single-institution experience of eight years. Urol Int 201 1;87:59-63. http://dx.doi.org/10.1159/000326761

12. Swanson DA, Borges PM. Complications of trans-abdominal radical nephrectomy for renal cell carcinoma. J Urol 1983;129:704-7

13. Delany HM. Spare the spleen: Rationale and techniques. J Natt Med Assoc 1990;82:577-9.

14. Berry MF, Rosato EF, Williams NN. Dexon mesh splenorrhaphy for intraoperative splenic injuries. Am Surg 2003;69:176-80.

15. Reddy CG, Chalasani V, Pathma-Nathan N. Splenic preservation: An additional haemostatic measure during mesh splenorhaphy. ANZ J Surg 2004;74:596-7. http://dx.doi.org/10.1111/i.14452197.2004.03065.x

16. Canby-Hagino ED, Morey AF, Jatoi I, et al. Fibrin sealant treatment of splenic injury during open and laparoscopic left radical nephrectomy. J Urol 2000;164:2004-5. http://dx.doi.org/10.1016/S0022$5347(05) 66939-X$

17. Biggs $G$, Hafron J, Feliciano J, et al. Treatment of splenic injury during laparoscopic nephrectomy with BioGlue, a surgical adhesive. Urology 2005;66:882. http://dx.doi.org/10.1016/i.urology.2005.04.054

Correspondence: Dr. Subhasis K. Giri, University Hospital Limerick, St. Nessan's Road, Limerick, Ireland; s21giri@yahoo.co.uk 